\title{
An AATP Model Based on CTP for Two-stage Production System
}

\author{
Lixi Yang \& Yan Fu \\ School of Mechanical Science and Engineering, Huazhong University of Science \& Technology \\ Wuhan 430074, China
}

Tel: 86-27-8755 $7840 \quad$ E-mail: laura_fy@mail.hust.edu.cn

\begin{abstract}
To realize that enterprise can quickly respond customer orders and ensure the reliability and optimization of the promise, in this article, we put forward a model of AATP (Allocated Available to Promise) based on CTP (Capacity to Promise). Aiming at some disadvantages in the quick response of order and comprehensive optimization, this model allocate future capacity to forecasted demands through considering market forecasted demands and comprehensively thinking over some restrictions such as enterprise object, material supply and capacity. The model establishes AATP for customer sales representative and offers the material requirement plan and the capacity requirement plan to ensure order promise. This model can support quick, reliable and optimized order promise decisions and realize synchronized procurement, production and sale for the enterprise.
\end{abstract}

Keywords: Capable to promise (CTP), Allocated available to promise (AATP), Two-stage production

\section{Introduction}

The economic globalization and the development of e-business make customer can select suppliers in the whole world with lower costs, and place order on the internet and require real-time response of the order form. If enterprises can not quickly respond customers' order, they may lose customers, and if enterprises can not deliver the goods in time, it will influence customers' loyalty, which also may lose customers (Stadtler, 2005, p.575-588). Therefore, the ability which can quickly respond customers' orders is the basic premise to acquire the core competition for enterprises. The order promise function connects with front-end customer demand management and back-end production and logistical system, offers ATP (Available to Promise) to synchronize procurement, production, distribution and sales, ensures enterprise can effective deploy supply chain capacity according to customers' demands, and offers powerful decision support to quickly respond order and realize profits.

In the mode of MTS (Make to Stock), the finished product inventory and the part that has not promised to customers in production plan are taken as ATP (Blackstone, 1998). With the transformation of production mode from MTS to MTO (Make to Order), researchers extend ATP and put forward CTP (Capacity to Promise) and AATP (Allocated Available to Promise). The former means to take the capability of material supply, production resource and transportation resource as the proof of order promise. And the later means to allocate planned promise capacity for different customers and products in advance. Taylor and Plenert put forward an approach for calculate ATP called as FCP (Finite Capacity Promising) (Taylor, 1999, p.50-56). The method of FCP supports a continuous monitoring of the resource capacity over the scheduled horizon and accordingly figure out the order due date. Jeong et al develop an ATP model for compute the promised delivery date and the unused capacity at shop floor level, and develop a heuristic algorithm which allocates customers' orders to unused capacity according to the customer specific due dates (Jeong, 2002, p.191-212). Xiong et al present a decision support system approach to compute ATP. They develop a heuristic approach to respond one specific order enquiry and several at a time, respectively (Xiong, 2006, p.332-346). Zhao et al take the Toshiba electric product supply chain as the application case, supported the ATP system though mixed integer programming model as viewed from the resource allocation, and made promise for all orders that arrive within a pre-determined batching interval and offered advices for production plans (Zhao, 2005, p.65-85).

Above articles mainly study the problem to establish demand allocation plan after actual orders arrive, but because arrived orders are just one part of demands, so the established ATP is just the local optimized plan. Though demand allocation plan can be established based on batching orders, so the plan can be improved to some extent, but some problems such as overlong order response time occur.

In this article, we take the order promise of two-stage production system as the research object, comprehensively consider constraints such as enterprise strategy, material supply, production resource and market demand, study the mapping model from low layer resources (material and production resources) to high layer resources (products), and offer decision supports for real-time order responses.

\section{Description of the problem}

According to the definition of ATP from APICS (American Production and Inventory Control Society), Customer 
sale representatives process customers' orders and inquire whether the finished product inventory can fulfill the demands of order, and if the condition is fulfilled, so they accept the order, or else, inquire whether the main production schedule can fulfill the demands of order, and if the condition is fulfilled, so they accept the order, or else, they should compute CTP cooperating with production planning department, and if the capacity can fulfill the demands, they accept the order, or else, they will reject this order requirement. It is obvious that the order promise process mainly includes finished product inventory inquiry, main production schedule inquiry and CTP, and the computation of former two activities is mainly to inquire database, which is comparatively simple.

Under the strategy of MTS, enterprises arrange production according to plans, and the finished product inventory and main production schedule are fit to be as the reference of order promise. However, the enterprise adopting the strategy of MTO has no finished product inventory, and the main production schedule can not effectively support the order promise decision because the horizon of main production schedule has long time span, the planned objects are generally product variety, and the demand of customer order usually acquire appointed product and deliver time. Through analysis, we can see that MTO enterprises have three disadvantages to implement above order flow. First, because to compute CTP we need firstly acquiring the data of material availability (including raw material inventory, scheduled receipts, supply situation of suppliers, and work in process), resource availability (including resource capacity, load and so on), and order requirement information, but these information may be distributed in some departments such as sales, material planning and production site, so it has certain difficulties to exactly obtain these information, if we recollect all relative information to compute CTP when we accept an order, even the economy can not be feasible. Second, because arrived orders are only one part of requirements, so to allocate demands without the consideration of future order will make the plan of ATP has no comprehensive optimization. At last, this promise mode is to allocate order demands according to the strategy of FCFS (First Come First Serve), i.e. all orders enjoy same treatment without differences of order profit, customer importance, and though this strategy represents certain justice, but its results will induce decreases of profit margin, customer relationship and other performance levels.

Therefore, Dell and other enterprises have set up their order promise flow fit for their own enterprise production characters. Dell divides customers into three sorts including Transaction, Relationship and International Customer, and every big sort has smaller classification. The Relationship customers means middle and large sized enterprises which will purchase over millions dollars' products from Dell, and the sales profits from these enterprises are higher, and are the most important source of the whole profits of Dell. Dell adopts different demand allocation strategies for different types of customer. Dell takes the Relationship customers as its emphasis, which makes the sale from these customers enhanced from 50\% of total sale in 1992 to $70 \%$ in 1997, and makes the Dell obtain compelling developments (Kraemer, 2000, p.5-21).

In this article, we establish the order promise mode shown in Figure 1 according to the order promise flow of Dell, which is called as AATP based on CTP. This mode decides quantum for various customers or products in advance, and when customer's order arrives, the customer sale representatives can quickly respond the customer order through the inquiry of AATP. The capacity promise computation in Figure 2 includes the AATP model base on CTP and algorithm engine, and under the triggers of time point or event, information such as enterprise strategy, product structure (including bill of material and product process route), factory structure (including production, transportation and various resources), capacity load (including released orders, planned orders receipts and equipment maintenance), material availability (including raw material inventory, scheduled receipts, supply restriction, work in process), predictive demands and confirmed orders will be updated to the AATP model based on CTP, and the algorithm engine will reallocate demands and educe AATP. Under the condition considering future demands, to implement order promise, the AATP model based on CTP will help to realize capacity optimization deployment, enhance customer service level and enterprise profitable aim for the enterprise. It's worth mentioning that when making order promise decisions, the material supply and production resources have been confirmed, so we can consider more details in the AATP model based on CTP, which is different with inventory plan models. In the following text, we take the two-stage production system as the object, and establish the AATP mathematical programming model based on CTP.

\section{AATP model based on CTP}

\subsection{Hypothesis of the model}

(1) The system structure and flow of two-stage production are seen in Figure 2, which is composed by some assembly lines and some shop floors, produces various products, and completes the final assembly works on the assembly line. Components composing final products partly come from various shop floors, and others are outsourcing. All parts to produce component in the plant come from outsourcing.

(2) When adopting the strategy of MTO, the situation that produce stock goods beforehand in finished products will 
not happen, and the subassembly can produce stock goods in advance.

(3) The purchase of material considers lead time, and has constraints of the least and the most purchase quantity.

(4) The production lead time of component and finished product should be considered. The production of components and finished products need occupying the capacity of shop floors or assembly lines.

(5) The transportation time from shop floors to assembly line will be ignored.

(6) The happening time points of the $t^{\prime}$ th material requirement and the $t^{\prime}$ th scheduled receipts are all at the beginning of the $t^{\prime}$ th period. The $t^{\prime}$ th finished product predictive demands and order requirements are fulfilled at the end of the t'th period. The happening time points of planned order receipts in the $t^{\prime}$ th period are all at the end of the $t^{\prime}$ th period.

\subsection{Mathematic model}

3.2.1 Model suffix set and suffixes

FNL: finished products.

CMP: components.

PRT: parts.

ITM: including all materials such as finished products, components and parts.

OUT: the components and part from outsourcing.

The suffix "p, q $\in$ ITM" denotes materials, and in specific situation, which means finished products FNL, components CMP, parts PRT or members of OUT.

FAB: shop floor.

MRG: assembly line.

PRD: all production units including FAB and MRG.

RES: machine tool and other production resources.

The suffix " $f \in P R D$ " denotes production unit, and in specific situation, which means members of FAB or MRG, and the suffix o $\in$ RES.

DUR: planned period. The |DUR| denotes the total of planned periods.

The suffix " $t \in$ DUR" denotes the $t$ 'th period in the plan.

\subsubsection{Model parameters}

PRCp: the sales price of the finished product $\mathrm{p}$.

HLDp: the inventory holding cost of unit quantity material $p$ in unit time.

REQ1q,p: the quantity of component $\mathrm{p}$ needed to assemble unit finished products $\mathrm{q}$.

REQ2q,p: the quantity of part $\mathrm{p}$ needed to produce unit component $\mathrm{q}$.

LTf,p: the lead time to produce products or subassembly $\mathrm{p}$ in the production unit $\mathrm{f}$.

BLTp: the purchasing lead time for outsourcing $\mathrm{p}$.

$\mathrm{RCPp}$,t: the quantity of outsourcing $\mathrm{p}$ planned in the beginning of the $t^{\prime}$ th period.

FAB_CMPf,p: if it is in existence, so the component $\mathrm{p}$ can be produced by the shop floor $\mathrm{f}$.

MRG_FNLf,p: if it is in existence, so the product $\mathrm{p}$ can be produced by the assembly line $\mathrm{p}$.

CAPf,o, RHOf,o, CCAPf,o: they respectively denote the production capacity, utilization rate and using cost of resource $\mathrm{o}$ in the production unit $\mathrm{f}$.

PCAPf,o,t: load of the resource $o$ in the production unite $f$ during the $t^{\prime}$ th period.

USGEf,o,p,m: the quality of the resource $o$ in the production unit $f$ needed to produce the unit product or component $\mathrm{p}$ during the $\mathrm{t}^{\prime}$ th period.

LLVLp, ULVLp: they respectively denote safety inventory and maximum inventory of part and component.

MINBUYp, MAXBUYp, CBUYp: they respectively denote the minimum purchase batch, the maximum purchase batch and the purchase price of unit quantity.

DEMp,t, ORDp,t: they respectively denote the predictive demand quantity and confirmed order quantity of the finished product $\mathrm{p}$ during the $\mathrm{t}$ 'th period. 


\subsubsection{Decision variables}

$\operatorname{atp}_{\mathrm{p}, \mathrm{t}}$ : the ATP of the finished product $\mathrm{p}$ in the $\mathrm{t}^{\prime}$ th period.

$\operatorname{prod}_{\mathrm{f}, \mathrm{p}, \mathrm{t}}$ : the quantity of the product or component $\mathrm{p}$ planned by the production unit $\mathrm{f}$ in the $\mathrm{t}^{\prime}$ th period.

$\operatorname{inv}_{\mathrm{p}, \mathrm{t}}:$ the inventory quantity of the material $\mathrm{p}$ in the initial of the $t^{\prime}$ th period.

buy $_{p, t}$ : the purchase quantity of the outsourcing $p$ in the initial of the $t^{\prime}$ th period.

ibuy $_{\mathrm{p}, \mathrm{t}}$ : whether purchase $\mathrm{p}$ during the $\mathrm{t}^{\prime}$ th period, and it is a binary variable, 1 represents true and 0 represents false.

$\mathrm{rsu}_{\mathrm{f}, \mathrm{o}, \mathrm{t}}$ : the capacity of the resource $\mathrm{o}$ in the production unit $\mathrm{f}$ planned to be used in the $\mathrm{t}^{\prime}$ th period.

\subsubsection{Objective function}

The model takes the maximum profits as its aim, i.e.

$$
\begin{aligned}
\operatorname{Max} \sum_{t \in D U R} & \left(\sum_{p \in F N L} P R C_{P} a t p_{p, t}-\sum_{p \in O U T} C B U Y_{p, t} b u y_{p, t}-\right. \\
& \left.\sum_{p \in I T M} H L D_{p} i n v_{p, t}-\sum_{f \in P R D} \sum_{o \in R E S} C C A P_{f, o} r s u_{f, o, t}\right)
\end{aligned}
$$

\subsubsection{Constraints equation}

(1) The demand constraint of finished products: the ATP should fulfill the confirmed order quantity at least, and shouldn't exceed the predictive demand quantity.

$$
\forall p \in F N L, \forall t \in D U R: O R D_{p, t} \leq a t p_{p, t} \leq D E M_{p, t}
$$

(2) Balance constraint of ATP: the ATP equals to the sum of planned output of all production units.

$$
\forall p \in F N L, t \in \text { DUR: } \operatorname{atp}_{p, t}=\sum_{f \in M R G} \operatorname{prod}_{f, p, t}
$$

(3) Balance constraint of part inventory: begin inventory + scheduled receipts + purchase quantity - wastage $=$ end inventory.

$$
\begin{aligned}
& \forall p \in P R T, t<|D U R|: \\
& i n v_{p, t}+R C P_{p, t}+b u y_{p, t}-\sum_{f \in F A B} \sum_{q \in C M P} R E Q 2_{q, p} \operatorname{prod}_{f, q, t+L T_{f q}-1}=i n v_{p, t+1}
\end{aligned}
$$

(4) Balance constraint of component inventory: begin inventory + scheduled receipts + purchase quantity - wastage $=$ end inventory.

$$
\begin{aligned}
& \forall p \in C M P, \forall t<|D U R|: \\
& i n v_{p, t}+R C P_{p, t}+\operatorname{buy}_{p, t}+\sum_{f \in F A B} \operatorname{prod}_{f, p, t}- \\
& \sum_{f \in M R G} \sum_{q \in F N L} R E Q 1_{q, p} \operatorname{prod}_{f, q, t+L T_{f q}-1}=i n v_{p, t+1}
\end{aligned}
$$

(5) Component demand constraint: begin inventory + scheduled receipts + purchase quantity $\geq$ wastage.

$$
\begin{aligned}
& \forall p \in C M P, t \in D U R: \\
& \text { inv }_{p, t}+R C P_{p, t}+b u y_{p, t}-\sum_{f \in M R G} \sum_{q \in F N L} R E Q 1_{q, p} \operatorname{prod}_{f, q, t+L T_{f q}-1} \geq 0
\end{aligned}
$$

(6) The constraint of outsourcing lead time.

$$
\forall p \in O U T, t<B L T(p): \text { buy }_{p, t}=0
$$

(7) Purchase quantity constraint of outsourcing: the purchase quantity should fulfill the minimum and maximum purchase batch.

$$
\begin{aligned}
& \forall p \in O U T, \forall t \in \text { DUR: } \\
& \text { ibuyp, } t \in\{0,1\} \\
& \text { ibuy }_{p, t} \leq \text { buy }_{p, t} \\
& \text { ibuy }_{p, t} \text { MINBUY }_{p} \leq \text { buy }_{p, t} \leq \text { ibuy }_{p, t} \text { MAXBUY }_{p}
\end{aligned}
$$

(8) Inventory capacity constraints: it needs the inventory is in the upper limit and the lower limit.

$$
\forall p \in P R T \mathrm{U} C M P, \forall t \in D U R: L L V L_{p} \leq i n v_{p, t} \leq U L V L_{p}
$$




$$
\begin{aligned}
& \forall p \in P R T, t=|D U R|: \\
& L L V L_{p} \leq i n v_{p, t}+R C P_{p, t}+b u y_{p, t}-\sum_{f \in F A B} \sum_{q \in C M P} R E Q 2_{q, p} \operatorname{prod}_{f, q, t+L T_{f q}-1} \leq U L V L_{p} \\
& \forall p \in P R T, \forall t=|D U R|: \\
& L L V L_{p} \leq i n v_{p, t}+R C P_{p, t}+b u y_{p, t}+\sum_{f \in F A B} \operatorname{prod}_{f, p, t}- \\
& \sum_{f \in M R G} \sum_{q \in F N L} R E Q 1_{q, p} \operatorname{prod}_{f, q, t+L T_{f q}-1} \leq U L V L_{p}
\end{aligned}
$$

(9) Lead time constraint of component production.

$$
\forall f \in F A B, \forall p \in C M P, t<L T(f, p): \operatorname{prod}_{f, p, t}=0
$$

(10) Balance constraint of resource capacity.

$$
\begin{aligned}
& \forall f \in P R D S, \forall o \in R E S, \forall t \in D U R: \\
& \sum_{p \in C M P \cup F N L} \sum_{m=1}^{L T(f, p)} U S G E_{f, o, p, m} \operatorname{prod}_{f, p, t+L T_{f p}-m+1}=r s u_{f, o, t}
\end{aligned}
$$

(11) Upper limit constraint of resource capacity.

$$
\forall f \in P R D, \forall o \in R E S, \forall t \in D U R: r s u_{f, o, t} \leq R H O_{f, o} C A P_{f, o}-P C A P_{f, o, t}
$$

(12) Non-negative constraint.

$$
\forall f \in P R D, \forall p \in C M P \mathrm{U} F N L, \forall t \in D U R: \operatorname{prod}_{f, p, t} \geq 0
$$

\subsection{Model explanation}

Model hypothesis: profits $=$ sale - (purchase cost of material + inventory holding cost + using cost of production resource), and take the maximum profit as the object.

The constraint equation (8) introduces the variable $i b u y p, t \in\{0,1\}$, so the model is the mixed integer programming problem. Most constraint equations in the model are obvious and have certain explanations, and we only simply explain the resource capacity balance constraint. Supposed that the lead time of the product $\mathrm{p}$ in the production unit $\mathrm{f}$ is $\mathrm{LT}_{\mathrm{f}, \mathrm{p}}$, so when the product $\mathrm{p}$ with unit quantity is in the $\mathrm{m}^{\prime}$ th of production process $\left(1 \leq \mathrm{m} \leq \mathrm{LT}_{\mathrm{f}, \mathrm{p}}\right)$, it needs occupying the quantity of the production resource $\mathrm{o}, \mathrm{USGE}_{\mathrm{f}, \mathrm{o}, \mathrm{p}, \mathrm{m}}$, and because in the t'th period of the plan, the product $\mathrm{p}$ in the m'th period will be produced, so the in the t'th period the quantity that this batch of product

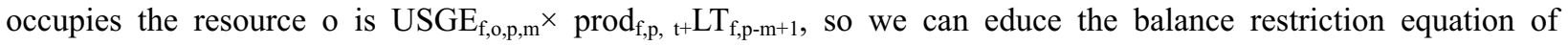
resource ability (13).

\section{Application of the model}

The AATP optimized model based on CTP under the strategy of MTO in this article has the ability to map the lower layer resources to the higher layer resources, and if we extend this model a little, it will solve many applied problems. For example, if defining the finished product in the model as the product that certain customer demands, so the computation results of the model can allocate ATP among different customers, and if taking the actual sales price subtracting non-key material stock costs and the manufacturing cost of non-key resource as the sales price in the model, so this model can be used to make the AATP plan only aiming at key material and key resources. Because this model takes the maximum profits as its aim, the phenomenon that the planned distribution quantity atp $\mathrm{p}_{\mathrm{t}, \mathrm{t}}$ may be smaller may occur in the computation results, which will induce lower customer service level. We define the demand fulfillment rate of the product $p$.

$$
s_{p}=\sum_{t \in D U R} a t p_{p, t} / D E M_{p, t}
$$

Add the constraint $s_{p} \geq S R V C \_L V L_{p}$ in the model, so the demand fulfillment rate of the product $p$ should exceed the requirement of SRVC_LVL . Similar methods also can be used to balance line loads. Replace the making units such as shop floor and assembly lines in this model by the making unit in the global supply chain environment, and consider the transportation resource constraint, this model can offer decision supports for the order promise in the network environment of global supply chain.

Furthermore, when every period ends, through updating order data, demand prediction, material supply, inventory strategy, load, scheduled receipts and other information, reallocate the AATP of the next period, this model can implement rolling plans. 


\section{Conclusions and expectation}

In this article, we establish an example of AATP based on CTP. In the example, three assembly lines and two shop floors compose the two-stage production system, produce four sorts of product, and compute the ATP in six periods. The model is developed through the optimized software Dash Xpress. The computation results show the AATP, planned production of various production unites, material requirement plan and capacity requirement plan of four sorts of products. Comparing with other order promise methods, the AATP model based on CTP can quickly respond customer orders and ensure the reliability and optimization of promise plan, and can identify outsourcing bottleneck through the material requirement plan, and identify the resource bottleneck through the capacity requirement plan.

However, in the actual applications of enterprises to support order promise decisions, following aspects should be noticed and studied. First, the product variety involved in actual enterprises may be thousands of sorts, and the demand prediction may be more complex, and the precise of demand prediction will influence the effects of this model to a large extent, so it is necessary to study the demand prediction problem under numerous products. Second, actual products have complex structures, the materials composed the product has ten thousands of sorts, and the manufacturing process has hundreds of procedures, which makes this model become the large scale optimization problem. So we should find out the solution technology for the large scale optimization problem. Third, this model needs acquiring relative information from the cooperative systems, and these cooperative systems are always heterogeneous, so it is a valuable study direction to acquire model input information from heterogeneous systems conveniently and timely.

\section{References}

Blackstone J. H. \& Cox J. F. (1998). APICS Dictionary. No.11. Virginia: Falls Church.

Evans M. K. (2002). Practical Business Forecasting. Blackwell Publishers.

Jeong B., Sim S.-B., Jeong H.-S., et al. (2002). An Available-to-promise System for TFT LCD Manufacturing in Supply Chain. Computers and Industrial Engineering. No.43. p.191-212.

Kraemer K. L., Dedrick J. \& Yamashiro S. (2000). Refining and Extending the Business Model with Information Technology: Dell Computer Corporation. The Information society. No.16(1). p.5-21.

Stadtler H. (2005). Supply Chain Management and Advanced Planning, Basics, Overview and Challenges. European Journal of Operational Research. No.163(3). p.575-588.

Taylor S. G. \& Plenert G. J. (1999). Finite Capacity Promising. Production and Inventory Management Journal. No.40(3). p.50-56.

Xiong M. H., Tor S. B., Bhatnagar R., et al. (2006). A DSS Approach to Managing Customer Enquiries for SMEs at the Customer Enquiry Stage. International Journal of Production Economics. No.103(1). p.332-346.

Zhao Z.-Y. \& Ball M. O. (2005). Optimization-based Available-to-promise with Multi-stage Resource Availability. Annals of Operations Research. No.135(1). p.65-85.

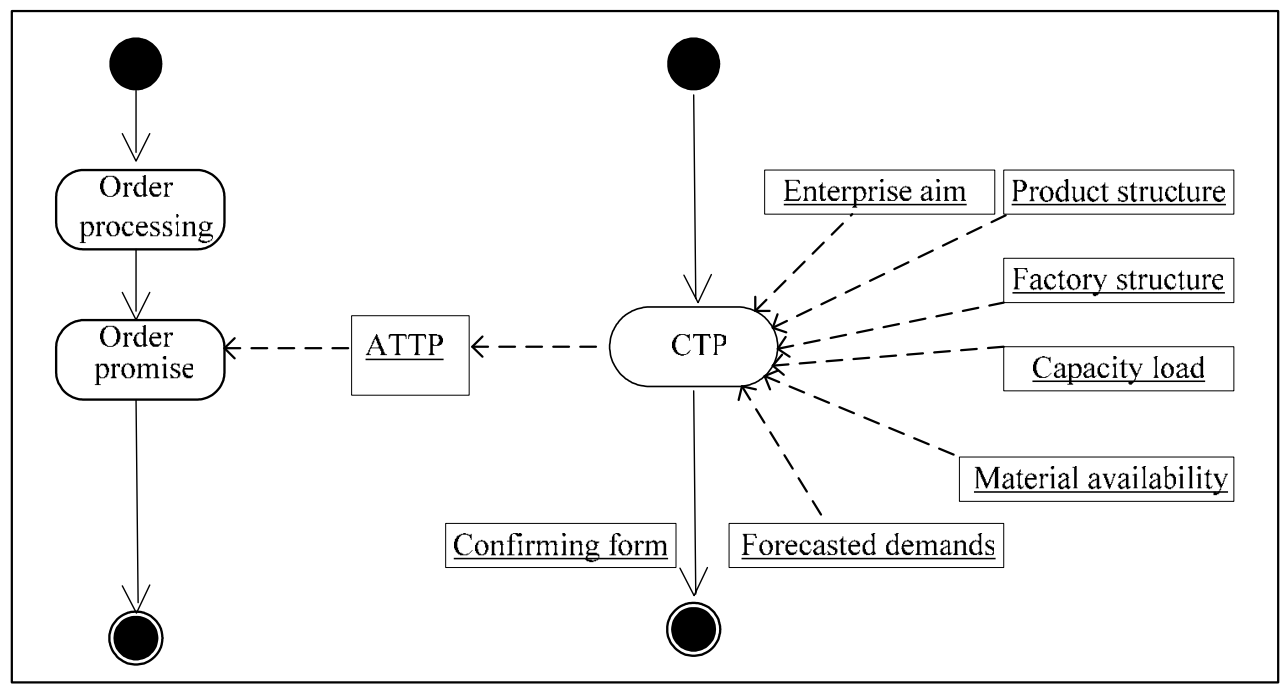

Figure 1. ATTP Order Promise Mode Based on CTP 


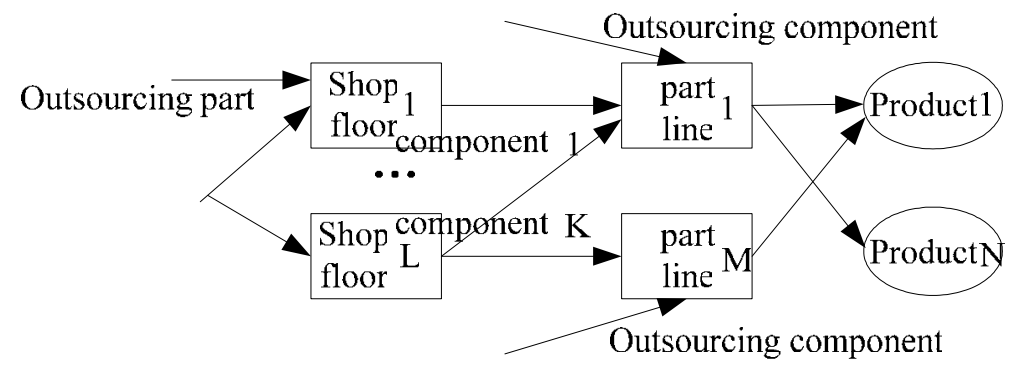

Figure 2. Sketch Map of Product Structure and Production Flow 